\title{
Posicionamiento de la lectura como habilidad transversal en planes de estudio para docentes de I y ll ciclos en Costa Rica
}

\author{
The position of Reading as a transversal skill in the study programs \\ for primary school teachers in Costa Rica. \\ Posicionamento da leitura como habilidade transversal nos currículos \\ para professores de I e Il ciclos na Costa Rica.
}

\author{
Rosemary Castro Solano \\ Universidad de Costa Rica \\ San José, Costa Rica \\ rosemary.castrosolano@ucr.ac.cr
}

(iD) https://orcid.org/0000-0002-4333-0363

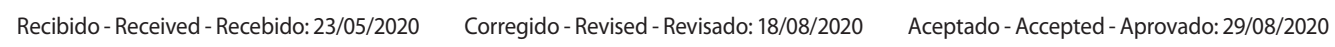

DOl: https://doi.org/10.22458/ie.v22i33.3013

URL: https://revistas.uned.ac.cr/index.php/innovaciones/article/view/3013

\begin{abstract}
Resumen: El artículo emana de la investigación realizada en el nodo Costa Rica de la Red para la Lectoescritura Inicial de Centroamérica y el Caribe (RedLEI) y en concreto la publicación busca responder si la secuencia didáctica de los planes de estudio aborda la lectura de las personas docentes en formación como habilidad transversal o si se limita a su abordaje instrumental como materia de enseñanza y en bloques curriculares aislados. Para ello, se realizó un mapeo de las carreras activas de Educación para I y II Ciclos y se analizaron sus planes de estudio por medio de la categorización de sus materias en cuatro dimensiones: Español (general), Lectoescritura, Didáctica de la Lengua y Literatura Infantil para analizar la cantidad de cursos en cada una, su creditaje y la secuencia didáctica según su ubicación en la malla curricular como caracterización cuantitativa de cómo los planes de estudio abordan la destreza a nivel de titulación inicial. Los resultados obtenidos para los 19 planes de estudio analizados permiten concluir que la mayoría $(n=11)$ de planes de estudio de titulación inicial docente para I y II ciclos centran su atención en las didácticas - ya sea de lectoescritura, de lengua o ambas sin preparar previamente a la persona docente en formación de destrezas lingüísticas generales y/o promover sus propios hábitos de lectura extensiva por medio de acciones formativas específicas en cultura lectora a nivel de plan de estudios, lo cual ciertamente socava la aspiración país de formar nuevas generaciones de docentes lectoras y lectores.
\end{abstract}

Palabras clave: Lectura, Docentes, Costa Rica, Formación de educadores de primaria, Escuela de profesores, Universidad 
Abstract: This article results from the research developed by the Costa Rican branch of The Central American and Caribbean Early Literacy Network (RedLEl) and in particular, this paper seeks to define whether the didactic sequence of the study programs for teachers in training approach reading as a transversal skill or if their approach is merely instrumental as a teaching subject and in isolated curricular blocks. To do this, a mapping of the current Primary Education undergraduate programs. Also, analyses and categorization of their courses were made in four dimensions: Spanish (general), Literacy, Didactics of Children's language, and literature. Aspects considered as quantitative characterization of how the programs approach the skill at the undergraduate stage were: number of courses offered, credits, and didactic sequence according to their position in the curriculum. The obtained results for the 19 study programs that were analyzed led to the conclusion that the majority $(n=11)$ of them focus their attention in the courses regarding the didactics when it comes to literacy, language, or both; without training or promoting reading habits and general language skills in prospect teachers through specific training actions in reading culture at a curriculum level. That certainly undermines the country's aspiration to train a new generation of teachers who are avid readers themselves.

Keywords: Reading, teachers, Costa Rica, primary school teacher training, teacher training, university.

Resumo: $O$ artigo baseia-se na pesquisa realizada no nó Costa Rica da Rede de Alfabetização Inicial na América Central e Caribe (RedLEl- Red para la Lectoescritura Inicial de Centroamérica e o Caribe). Especificamente, a publicação procura responder se a sequência didática dos currículos aborda a leitura de professores em formação como habilidade transversal ou se ela somente se limita à abordagem instrumental como disciplina de ensino e em blocos curriculares isolados. Para tal fim, foi feito um levantamento das carreiras ativas de Educação para I e II Ciclos e os seus currículos foram analisados categorizando suas disciplinas em quatro dimensões: Espanhol (geral), Alfabetização, Didática de Línguas e Literatura Infantil para analisar o número de cursos em cada um, seus créditos e a sequência didática de acordo com localização na grade curricular como caracterização quantitativa de como os currículos abordam a competência no nível de graduação inicial. Os resultados obtidos para os 19 currículos analisados permitem concluir que a maioria ( $n=11)$ dos currículos de formação inicial de professores para I e Il ciclos focalizam a sua atenção na didática - seja leitura e escritura, língua ou ambas - sem preparar previamente o professor em formação de habilidades linguísticas gerais e/ou promover seus próprios hábitos de leitura extensiva através de ações de formação específica em cultura de leitura no nível de currículo, o que certamente mina a aspiração do país de formar gerações de professores leitores.

Palavras-chave: Leitura, professores, Costa Rica, formação de educadores primários, escola de professores, Universidade. 


\section{INTRODUCCIÓN}

A pesar de la gran cantidad de recursos que el Estado costarricense destina al rubro educativo y que constituye la inversión educativa per cápita más alta en Latinoamérica - 7,6\% PIB - según datos de la UNESCO (Presidencia de la República, 2015), dicha inversión no parece reflejarse en el desempeño de sus estudiantes en pruebas internacionales, tal como lo advierte la Organización para la Cooperación y el Desarrollo Económico (Cerdas, 2017) y lo cual resulta alarmante si se considera que, además de las deficiencias históricas que el logro educativo costarricense muestra en matemática, actualmente los resultados de mediciones estandarizadas como el Programa Internacional para la Evaluación de Estudiantes (PISA) evidencian retrocesos en ciencias y en lectura. De este modo, aunque el país se ubica en el tercer lugar en América Latina en rendimiento en las tres competencias - matemáticas, ciencias y lectura - a escala global las puntuaciones de las y los estudiantes costarricenses se ubican por debajo del promedio de naciones que invierten mucho menos en educación (op.cit.).

Específicamente en materia de comprensión lectora, las pruebas PISA efectuadas en 2018 arrojaron que el país obtuvo una puntuación de 426 puntos - frente a la media OCDE (Organización para la Cooperación y el Desarrollo Económico) de 467 - lo cual representa un descenso con respecto a los 427 puntos obtenidos en 2015 y a los 436 puntos obtenidos en 2012 (Cerdas, 2019b). Adicionalmente, el resultado de las y los estudiantes costarricenses en las pruebas de Lectura del Estudio TERCE 2015 fue el segundo mejor a nivel regional (754 puntos, sólo superado por Chile con 802 puntos) pero, al desagregar este hallazgo con datos del PEN (2017), se evidencia que la mayoría (45\%) se ubica con comprensión lectora a nivel literal-inferencial y, aunque el porcentaje de estudiantes con compresión lectora exclusivamente literal es muy bajo (5\%), los resultados para los niveles inferencial-crítico (25\%) y crítico (25\%) siguen indicando la necesidad de afinar las estrategias didácticas en lectura.

Al respecto, el Séptimo Informe del Estado de la Educación publicado en 2019 se enfocó en la capacidad docente para implementar los nuevos planes de estudio de Español del Ministerio de Educación Pública (MEP) y concluyó que apenas la mitad de los educadores que imparten dichos programas estarían en capacidad de dar una buena enseñanza en materia de lectura y escritura y que la aplicación de técnicas para instruir a niños y jóvenes en esta área varía según la formación universitaria recibida. Asimismo, el informe dentro de su análisis considera vital fortalecer la capacidad lectora de los docentes pues afirma que, si los docentes no leen, difícilmente se podrá esperar que los niños lean y no siempre es una práctica recurrente (Cerdas, 2017b).

Aún más, como resultado del informe, el MEP se dio a la tarea de construir el marco de cualificaciones para las carreras de docencia que buscará "promover la calidad en la formación y mejorar los criterios de contratación de los futuros profesionales en Educación de manera tal que estos demuestren altos estándares antes de llegar a las aulas costarricenses" (Castro, 2020a), en especial por el hecho de que las estadísticas del informe consignan que en Costa Rica se gradúan cerca de diez mil nuevos docentes cada año.

El Marco Nacional de Cualificaciones fue presentado el pasado 21 de febrero de 2020 como conjunto de resultados de aprendizaje para las carreras de Educación que se miden en los siguientes indicadores mínimos del "perfil del docente deseable" al ser contratado por el MEP (op.cit.):

- Conoce los programas del MEP aprobados por el Consejo Superior de Educación;

- domina el conocimiento disciplinar, los enfoques y las didácticas de enseñanza específicas para sus saberes;

- generar en sus alumnos capacidades de pensamiento complejo;

- reflexiona críticamente sobre su práctica educativa y realiza investigaciones; 
- es lector, así como capaz de promover la compresión lectora y las habilidades comunicativas de los estudiantes;

- maneja un segundo idioma;

- posee un conocimiento de los principales avances y hallazgos más recientes de las neurociencias;

- utiliza las nuevas tecnologías de la información y de la comunicación;

- se convierte en docente líder, flexible, innovador y propositivo;

- media en el conocimiento para que sus estudiantes comprendan las ideas;

- posee competencias socioemocionales suficientes para poder proyectarlas en el aula.

El MEP espera que la construcción de este "Marco Nacional de Cualificaciones" - que se encuentra en su primera etapa y se espera esté concluido para finales de año de modo que se implemente a partir de 2021 - permita "proporcionar mayor coherencia a la formación universitaria, rediseñar planes de estudio y elevar la calidad de la educación, así como mejorar los procesos de contratación y evaluación del desempeño docente" (Cerdas, 2020).

En el marco de esta coyuntura nacional de revisión de la formación docente, la investigación realizada planteó explorar la promoción al interés lector durante la formación docente inicial en Costa Rica que imparten las universidades públicas y privadas en el área de Educación para I y II Ciclos y, para ello, comenzar por analizar el posicionamiento de la lectura como habilidad transversal en los planes de estudio de formación inicial, dimensionado según las siguientes variables:

- El posicionamiento, la intensidad y la secuencia didáctica de los contenidos relacionados con lectura y con lectoescritura en los planes de estudio;

- cursos dedicados al español (lengua general) y su creditaje;

- secuencia didáctica en español (lengua general) en la malla curricular;

- cursos dedicados a la enseñanza de la lectoescritura y su creditaje;

- secuencia didáctica en enseñanza de la lectoescritura en la malla curricular;

- cursos dedicados a la didáctica de la lengua y su creditaje;

- secuencia didáctica en didáctica de la lengua español en la malla curricular;

- cursos dedicados a la literatura infantil y su creditaje;

- secuencia didáctica en literatura infantil en la malla curricular.

\section{MATERIALES Y MÉTODOS}

Inicialmente, las unidades de análisis fueron los $26(\mathrm{~N}=26)$ programas de formación universitaria inicial de docentes de I y II ciclos mapeados en Costa Rica (tres programas en universidades públicas y 23 programas en universidades privadas) por lo que no se requirió una muestra (n) predeterminada pues se aplicó el criterio de auto-inclusión definido como interés manifiesto de participar en el estudio al contestar al cuestionario inicial.

Los hallazgos, a nivel de mallas curriculares, tuvieron como base el análisis exhaustivo de la oferta académica de universidades públicas y privadas en Educación para I y II Ciclos en Costa Rica y de los planes de estudio 
de cada carrera en el área pues, una vez realizado el mapeo inicial, los planes de estudio se analizaron según la documentación recibida del Consejo Nacional de Rectores (CONARE) en el caso de universidades públicas y del Consejo Nacional de Educación Superior Privada (CONESUP) para universidades privadas.

Seguidamente, la construcción de categorías se realizó con base en el nombre del curso y en su objetivo general, pues ambos aspectos junto con el creditaje deben permanecer invariables con respecto a los aprobados por los órganos antes mencionados y como adaptación de la categorización empleada por Marielos Murillo y Ana María Carmiol en 2008 -la cual estaba basada en las macrodestrezas lingüísticaspara categorizar las destrezas lingüísticas de lo general a lo específico: español (general), lectoescritura, didáctica de la lengua y literatura infantil.

Se procede entonces a presentar los resultados del mapeo de unidades de análisis, que resultó en $\mathbf{2 6}$ programas de formación universitaria inicial de docentes de I y ll ciclos en Costa Rica, tal como se consigna en la tabla1.

TABLA 1

Listado alfabético de universidades costarricenses que imparten formaciones iniciales (diplomado y/o bachillerato) en Educación con énfasis en I y II Ciclos

\begin{tabular}{|c|c|c|c|c|c|c|c|}
\hline \multirow[t]{2}{*}{ No. } & \multirow[t]{2}{*}{ Nombre de la universidad } & \multicolumn{2}{|c|}{$\begin{array}{l}\text { Origen y financiamiento } \\
\text { de la universidad }\end{array}$} & \multicolumn{2}{|c|}{$\begin{array}{c}\text { Áreas en las que imparten } \\
\text { formaciones iniciales en } \\
\text { Educación }\end{array}$} & \multicolumn{2}{|c|}{$\begin{array}{l}\text { Grado inicial ofrecido } \\
\text { como formación inicial en Educación }\end{array}$} \\
\hline & & Pública & Privada & Preescolar & I y || Ciclos & Preescolar & I y || Ciclos \\
\hline 1 & $\begin{array}{l}\text { FUNDEPOS ALMA MATER } \\
\text { (FUNDEPOS) }\end{array}$ & & $\sqrt{ }$ & $\sqrt{ }$ & $\sqrt{ }$ & Bachillerato & Bachillerato \\
\hline 2 & $\begin{array}{l}\text { Universidad de Cartago } \\
\text { Florencio del Castillo } \\
\text { (UCA) }\end{array}$ & & $\checkmark$ & $\checkmark$ & $\sqrt{ }$ & Bachillerato & Bachillerato \\
\hline 3 & $\begin{array}{l}\text { Universidad de Ciencias } \\
\text { Empresariales } \\
\text { (UCEM) }\end{array}$ & & $\sqrt{ }$ & $\sqrt{ }$ & $\mathscr{}$ & $\begin{array}{c}\text { Bachillerato } \\
\text { (Preescolar Bilingüe) }\end{array}$ & $\begin{array}{c}\text { Bachillerato } \\
\text { (I y |l Ciclo Bilingüe) }\end{array}$ \\
\hline 4 & $\begin{array}{l}\text { Universidad de las Ciencias } \\
\text { y el Arte de Costa Rica } \\
\text { (UNICA) }\end{array}$ & & & 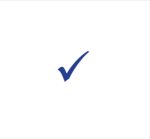 & 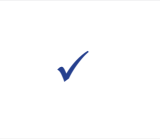 & Bachillerato & Bachillerato \\
\hline 5 & $\begin{array}{l}\text { Universidad de Costa Rica } \\
\text { (UCR) }\end{array}$ & $\checkmark$ & & $\checkmark$ & $\checkmark$ & Bachillerato & Bachillerato \\
\hline 6 & $\begin{array}{l}\text { Universidad de La Salle } \\
\text { (LA SALLE) }\end{array}$ & & $\sqrt{ }$ & $\sqrt{ }$ & $\sqrt{ }$ & Bachillerato & $\begin{array}{l}\text { Bachillerato (I y II } \\
\text { Ciclos en Español, I y } \\
\text { II Ciclos en Inglés, y I y } \\
\text { II Ciclos en Francés) }\end{array}$ \\
\hline 7 & $\begin{array}{l}\text { Universidad de San José } \\
\text { (USJ) }\end{array}$ & & $\sqrt{ }$ & & $\sqrt{ }$ & No se ofrece & $\begin{array}{c}\text { Bachillerato } \\
\text { (Enseñanza Primaria } \\
\text { con énfasis en } \\
\text { Español y Enseñanza } \\
\text { Primaria con énfasis } \\
\text { en Inglés) }\end{array}$ \\
\hline 8 & $\begin{array}{l}\text { Universidad Adventista } \\
\text { de Centroamérica } \\
\text { (UNADECA) }\end{array}$ & & $\checkmark$ & $\sqrt{ }$ & $\sqrt{ }$ & Bachillerato & Bachillerato \\
\hline
\end{tabular}




\begin{tabular}{|c|c|c|c|c|c|c|c|}
\hline \multirow[t]{2}{*}{ No. } & \multirow[t]{2}{*}{ Nombre de la universidad } & \multicolumn{2}{|c|}{$\begin{array}{l}\text { Origen y financiamiento } \\
\text { de la universidad }\end{array}$} & \multicolumn{2}{|c|}{$\begin{array}{c}\text { Áreas en las que imparten } \\
\text { formaciones iniciales en } \\
\text { Educación }\end{array}$} & \multicolumn{2}{|c|}{$\begin{array}{c}\text { Grado inicial ofrecido } \\
\text { como formación inicial en Educación }\end{array}$} \\
\hline & & Pública & Privada & Preescolar & | y || Ciclos & Preescolar & | y || Ciclos \\
\hline 9 & $\begin{array}{l}\text { Universidad Americana } \\
\text { (UAM) }\end{array}$ & & $\sqrt{ }$ & $\checkmark$ & $\checkmark$ & Bachillerato & Bachillerato \\
\hline 10 & $\begin{array}{l}\text { Universidad Autónoma } \\
\text { de Centroamérica } \\
\text { (UACA) }\end{array}$ & & & $\sqrt{ }$ & $\sqrt{ }$ & Bachillerato & Bachillerato \\
\hline 11 & $\begin{array}{l}\text { Universidad Católica } \\
\text { de Costa Rica } \\
\text { (CATÓLICA) }\end{array}$ & & 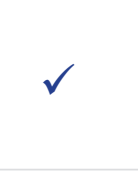 & $\checkmark$ & $\sqrt{ }$ & Bachillerato & $\begin{array}{c}\text { Bachillerato } \\
\text { (I y II Ciclos en } \\
\text { Español, I y II Ciclos } \\
\text { en Inglés) }\end{array}$ \\
\hline 12 & $\begin{array}{l}\text { Universidad Central } \\
\text { (UC) }\end{array}$ & & & $\sqrt{ }$ & $\sqrt{ }$ & $\begin{array}{c}\text { Bachillerato } \\
\text { (Preescolar y } \\
\text { Preescolar Bilingüe) }\end{array}$ & $\begin{array}{c}\text { Bachillerato } \\
\text { (I y II Ciclo y } \\
\text { I y II Ciclo Bilingüe) }\end{array}$ \\
\hline 13 & $\begin{array}{c}\text { Universidad Centroamericana } \\
\text { de Ciencias Sociales } \\
\text { (UCACIS) }\end{array}$ & & & $v$ & & Bachillerato & No se ofrece \\
\hline 14 & $\begin{array}{l}\text { Universidad Continental } \\
\text { de las Ciencias y las Artes } \\
\text { (UCCART) }\end{array}$ & & & $\sqrt{ }$ & & Bachillerato & No se ofrece \\
\hline 15 & $\begin{array}{l}\text { Universidad Cristiana } \\
\text { Internacional } \\
\text { (CRISTIANA INTL) }\end{array}$ & & & & & & Bachillerato \\
\hline 16 & $\begin{array}{l}\text { Universidad Estatal } \\
\text { a Distancia (UNED) }\end{array}$ & $\sqrt{ }$ & & 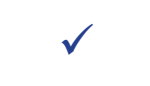 & $\sqrt{ }$ & $\begin{array}{l}\text { Diplomado y } \\
\text { Bachillerato }\end{array}$ & $\begin{array}{l}\text { Diplomado y } \\
\text { Bachillerato }\end{array}$ \\
\hline 17 & $\begin{array}{l}\text { Universidad Federada } \\
\text { de Costa Rica } \\
\text { (FEDERADA) }\end{array}$ & & & $\sqrt{ }$ & $\sqrt{ }$ & Bachillerato & Bachillerato \\
\hline 18 & $\begin{array}{l}\text { Universidad Fidélitas } \\
\text { (FIDELITAS) }\end{array}$ & & $\checkmark$ & $\sqrt{ }$ & $\sqrt{ }$ & Bachillerato & Bachillerato \\
\hline 19 & $\begin{array}{c}\text { Universidad } \\
\text { Hispanoamericana } \\
\text { (UH) }\end{array}$ & & & $\sqrt{ }$ & $\sqrt{ }$ & $\begin{array}{c}\text { Bachillerato } \\
\text { (Preescolar y } \\
\text { Preescolar Bilingüe) }\end{array}$ & $\begin{array}{c}\text { Bachillerato } \\
\text { (I y II Ciclo y } \\
\text { I y II Ciclo Bilingüe) }\end{array}$ \\
\hline 20 & $\begin{array}{l}\text { Universidad } \\
\text { Independiente } \\
\text { e Costa Rica } \\
\text { (UNICOR) }\end{array}$ & & 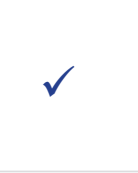 & & $\sqrt{ }$ & No se ofrece & Bachillerato \\
\hline 21 & $\begin{array}{l}\text { Universidad Internacional } \\
\text { de las Américas } \\
\text { (UIA) }\end{array}$ & & & $\sqrt{ }$ & & $\begin{array}{c}\text { Bachillerato } \\
\text { (Preescolar Bilingüe) }\end{array}$ & No se ofrece \\
\hline 22 & $\begin{array}{l}\text { Universidad Internacional } \\
\text { San Isidro Labrador } \\
\text { (UISIL) }\end{array}$ & & . & $\sqrt{ }$ & $\sqrt{ }$ & $\begin{array}{c}\text { Bachillerato } \\
\text { (Preescolar y } \\
\text { Preescolar Bilingüe) }\end{array}$ & $\begin{array}{c}\text { Bachillerato } \\
\text { (I y || Ciclo, y } \\
\text { I y || Ciclo Bilingüe) }\end{array}$ \\
\hline
\end{tabular}

Continúa... 


\begin{tabular}{|c|c|c|c|c|c|c|c|}
\hline \multirow[t]{2}{*}{ No. } & \multirow[t]{2}{*}{ Nombre de la universidad } & \multicolumn{2}{|c|}{$\begin{array}{l}\text { Origen y financiamiento } \\
\text { de la universidad }\end{array}$} & \multicolumn{2}{|c|}{$\begin{array}{c}\text { Áreas en las que imparten } \\
\text { formaciones iniciales en } \\
\text { Educación }\end{array}$} & \multicolumn{2}{|c|}{$\begin{array}{l}\text { Grado inicial ofrecido } \\
\text { como formación inicial en Educación }\end{array}$} \\
\hline & & Pública & Privada & Preescolar & | y || Ciclos & Preescolar & I y || Ciclos \\
\hline 23 & $\begin{array}{l}\text { Universidad Latina } \\
\text { de Costa Rica } \\
\text { (UNILAT) }\end{array}$ & & $\sqrt{ }$ & $\sqrt{ }$ & $\sqrt{ }$ & $\begin{array}{c}\text { Bachillerato } \\
\text { (Preescolar Bilingüe) }\end{array}$ & Bachillerato \\
\hline 24 & $\begin{array}{c}\text { Universidad } \\
\text { Latinoamericana } \\
\text { de Ciencia y Tecnología } \\
\text { (ULACIT) }\end{array}$ & & $\checkmark$ & $\sqrt{ }$ & & $\begin{array}{c}\text { Bachillerato } \\
\text { (Preescolar Bilingüe) }\end{array}$ & No se ofrece \\
\hline 25 & $\begin{array}{l}\text { Universidad Libre } \\
\text { de Costa Rica } \\
\text { (ULICORI) }\end{array}$ & & $\checkmark$ & & $\sqrt{ }$ & No se ofrece & $\begin{array}{c}\text { Bachillerato } \\
\text { (Enseñanza Primaria } \\
\text { con énfasis en } \\
\text { Español y Enseñanza } \\
\text { Primaria con énfasis } \\
\text { en Inglés) }\end{array}$ \\
\hline 26 & $\begin{array}{l}\text { Universidad Magister } \\
\text { (MAGISTER) }\end{array}$ & & $\sqrt{ }$ & $\sqrt{ }$ & & $\begin{array}{c}\text { Bachillerato } \\
\text { (Preescolar y } \\
\text { Preescolar Bilingüe) }\end{array}$ & No se ofrece \\
\hline 27 & $\begin{array}{l}\text { Universidad Metodista } \\
\text { (METODISTA) }\end{array}$ & & $\sqrt{ }$ & & $\sqrt{ }$ & & Bachillerato \\
\hline 28 & $\begin{array}{l}\text { Universidad Metropolitana } \\
\text { Castro Carazo } \\
\text { (UMCA) }\end{array}$ & & $\sqrt{ }$ & $\sqrt{ }$ & $\checkmark$ & Bachillerato & Bachillerato \\
\hline 29 & $\begin{array}{l}\text { Universidad Nacional } \\
\text { (UNA) }\end{array}$ & $\checkmark$ & & $\sqrt{ }$ & $\checkmark$ & Bachillerato & $\begin{array}{l}\text { Bachillerato } \\
\text { (I y II Ciclo y } \\
\text { I y II Ciclo en } \\
\text { Educación Rural) }\end{array}$ \\
\hline 30 & $\begin{array}{l}\text { Universidad Panamericana } \\
\text { (UPA) }\end{array}$ & & $\sqrt{ }$ & $\sqrt{ }$ & & $\begin{array}{c}\text { Bachillerato } \\
\text { (Preescolar Bilingüe) }\end{array}$ & No se ofrece \\
\hline 31 & $\begin{array}{l}\text { Universidad Politécnica } \\
\text { Internacional } \\
\text { (UPI) }\end{array}$ & & $\checkmark$ & & $\sqrt{ }$ & No se ofrece & Bachillerato \\
\hline 32 & $\begin{array}{l}\text { Universidad Santa Lucía } \\
\qquad \text { (USL) }\end{array}$ & & $\sqrt{ }$ & & $\sqrt{ }$ & No se ofrece & Bachillerato \\
\hline
\end{tabular}

Fuente: Elaboración propia (2018) con datos del Consejo Nacional de Rectores (CONARE, 2018) y del Consejo Nacional de Enseñanza Superior Universitaria Privada (CONESUP, 2018).

En consecuencia, se tienen los siguientes hallazgos de línea base de la formación docente inicial en Costa Rica:

- El número de programas a nivel inicial de Educación para I y ll Ciclos autorizados por los respectivos entes (Consejo Nacional de Rectores (CONARE) para las universidades públicas y Consejo Nacional de Enseñanza Superior Privada (CONESUP) para las universidades privadas) es de $26(\mathrm{~N}=26)$ con tres universidades públicas y 23 universidades privadas, pero no corresponde con los programas que actualmente se ofertan ( $n=19$ con tres universidades estatales y 16 universidades privadas). La reducción 
de la oferta proviene del hecho de que ocho universidades privadas han dejado de ofertar dichas titulaciones y, en su lugar, sólo mantienen abierta la matrícula en los programas con concentración en inglés, ya sea para preescolar, primaria o secundaria. El hecho, si bien debe leerse en el contexto de la oferta y la demanda, también plantea potencialmente un nuevo reto país en materia de lectoescritura en L1 (español) pues implica que un porcentaje importante de docentes de primaria que hoy se forman en universidades privadas reciben su formación en lectoescritura y en didáctica de la lengua para una L2 (inglés) y no para su L1 (español).

- En cuanto a acreditación de los programas por parte del Sistema Nacional de Acreditación de la Educación Superior (SINAES), solamente los programas de estudio de Educación para I y II Ciclos a nivel inicial ofrecidos por universidades estatales - tres instituciones de 19 que ofrecen formación docente inicial para I y II ciclo - han sido acreditados. Lo anterior resulta importante no sólo en materia de estandarización de los programas, sino que específicamente en lectoescritura inicial abre una ventana para proponer una certificación en el tema pues la vasta mayoría de programas de formación inicial docente en Educación para I y II Ciclos no cuentan con ningún sello de calidad asociado (lo anterior contrasta con la situación de las carreras de Enseñanza del Inglés - que forman docentes de secundaria - y que sí se encuentran acreditadas (a mayo 2019) en dos universidades privadas: Universidad Hispanoamericana y Universidad Americana. Llama la atención que estos dos establecimientos también ofrecen la carrera de Educación para I y II Ciclos pero, en ninguna de estas instituciones, el programa ha sido acreditado.

\section{RESULTADOS Y DISCUSIÓN}

El mapeo anterior permite así analizar los programas para determinar el posicionamiento de los temas relacionados con lectura y lectoescritura dentro de las mallas curriculares a nivel de número de cursos y creditaje de los mismos, así como de secuencia didáctica de estos programas en las áreas definidas. Primero, se ofrece un análisis de la carga de créditos necesarios para obtener la titulación inicial (ver nota 1) -bachillerato, en la vasta mayoría de instancias pues solamente dos instituciones afirman tener salidas laterales - como docente para I y II Ciclos en Costa Rica y la cual se encuentra entre 112 y 142 créditos (a nivel estatal, la Universidad Nacional (UNA) y la Universidad Estatal a Distancia (UNED) poseen salida lateral de diplomado (aproximadamente a los 65-70 créditos, ver tabla 4), mientras que en la oferta privada la Universidad Florencio del Castillo (UCA) posee las salidas laterales que corresponden a cada una de las escalas salariales establecidas por el Ministerio de Educación Pública (MEP).

La carga más alta se observa en un programa de estudios a nivel de bachillerato en una universidad estatal (UCR) pero esta diferencia de créditos no obedece necesariamente a un mayor número de cursos especializados, sino a la llamada formación transversal (cursos integrados de humanidades, seminarios de realidad nacional, repertorios, actividad artística y actividad deportiva). Asimismo, en todos los casos, la obtención del título inicial requiere completar una experiencia de Trabajo Comunal Universitario (TCU) cuya duración oscila - según cada universidad - entre las 150 horas (en las universidades privadas) y las 300 horas (en las universidades estatales).

Luego de hacer la comparación anterior, se procedió a analizar en detalle la formación que cada uno de estos 19 programas de estudio ofrece en lectoescritura y/o en lengua española general o didáctica de la lengua.

Tal como se expresó anteriormente, como adaptación de la categorización por macrodestrezas lingüísticas que hicieron Murillo y Carmiol (2008) en su ponencia para el Segundo Informe Estado de la Educación, se 
establecieron cuatro categorías para agrupar los cursos relacionados con identidad lectora de las futuras docentes y de los futuros docentes en un acercamiento del uso de la lengua para propósitos generales a su uso particular en la literatura creada específicamente para niñas y niños (ver nota 2), a saber:

- Español (general): núcleo de destrezas macro y micro lingüísticas en L1

- Lectoescritura: didáctica y/o técnicas de alfabetización

- Didáctica de la lengua: artes del idioma y pedagogías del español incluyendo expresión creativa

- Literatura infantil: acercamiento al texto literario

Así bien, la categorización realizada no solo refleja las disparidades existentes entre los 19 programas de estudio analizados en cuanto a intensidad (creditaje) de la formación en materia de lengua española general, lectoescritura, didáctica de la lengua y literatura infantil, según la universidad en la que estudien las futuras docentes y los futuros docentes sino que, a partir de la ubicación de los cursos en la secuencia didáctica de la malla curricular, permite inferir si el programa de estudios posiciona la lectura - y en general las destrezas lingüísticas - como habilidad transversal o si, por el contrario, la enfoca de manera más instrumental al limitarse a "enseñar cómo enseñar" las destrezas lingüísticas sin haber promovido primero su desarrollo en la persona docente en formación.

La tabla 2 detalla entonces la categorización realizada para los 19 planes de estudio analizados.

TABLA 2

Desglose de cursos en las áreas de lectoescritura, español general, didáctica de la lengua española y literatura infantil en los programas de estudio de formación inicial en Educación con énfasis en I y II Ciclos

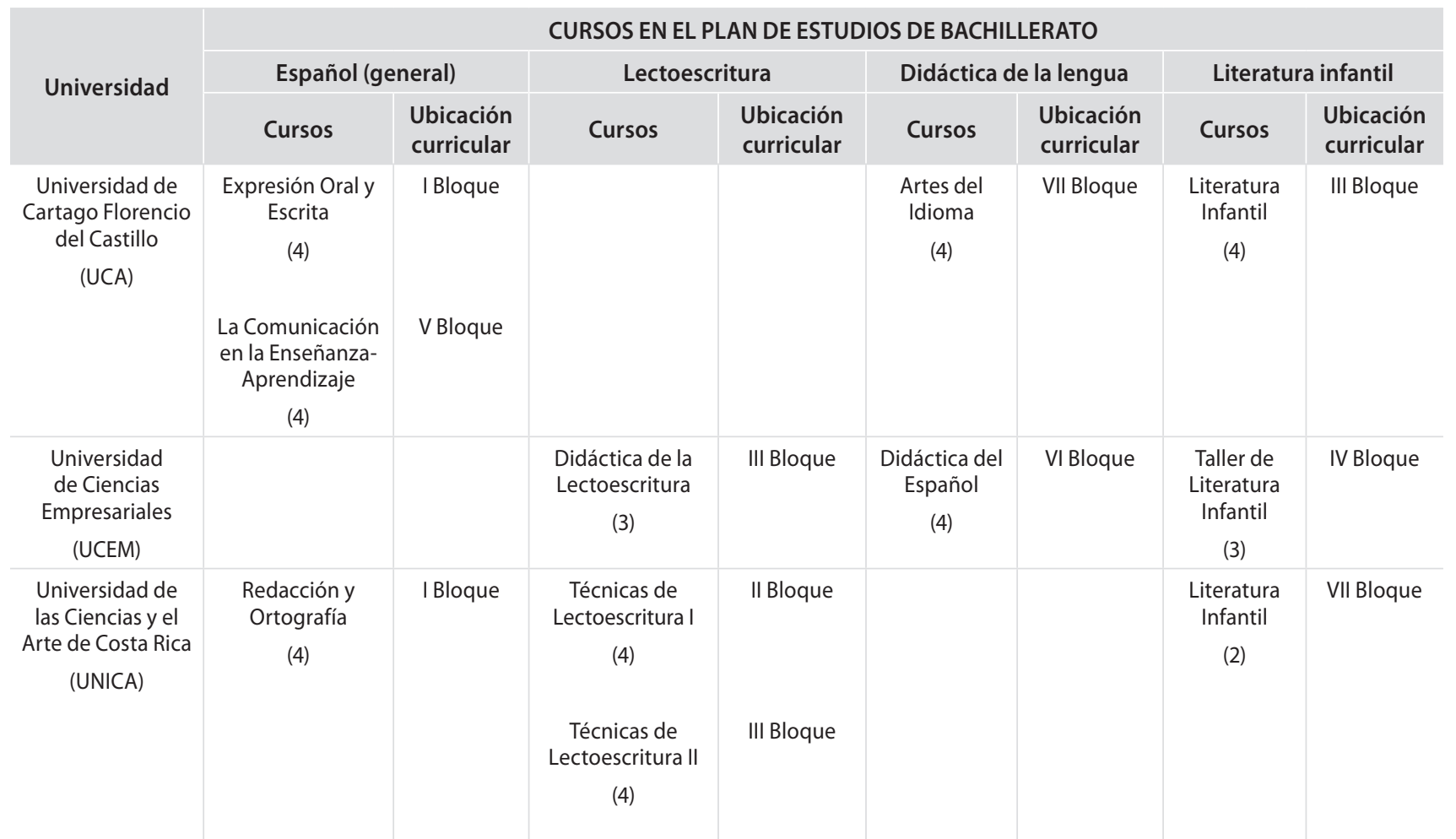

Continúa... 


\begin{tabular}{|c|c|c|c|c|c|c|c|c|}
\hline \multirow{3}{*}{ Universidad } & \multicolumn{8}{|c|}{ CURSOS EN EL PLAN DE ESTUDIOS DE BACHILLERATO } \\
\hline & \multicolumn{2}{|c|}{ Español (general) } & \multicolumn{2}{|c|}{ Lectoescritura } & \multicolumn{2}{|c|}{ Didáctica de la lengua } & \multicolumn{2}{|c|}{ Literatura infantil } \\
\hline & Cursos & $\begin{array}{l}\text { Ubicación } \\
\text { curricular }\end{array}$ & Cursos & $\begin{array}{l}\text { Ubicación } \\
\text { curricular }\end{array}$ & Cursos & $\begin{array}{l}\text { Ubicación } \\
\text { curricular }\end{array}$ & Cursos & $\begin{array}{l}\text { Ubicación } \\
\text { curricular }\end{array}$ \\
\hline $\begin{array}{l}\text { Universidad de } \\
\text { Costa Rica } \\
\text { (UCR) } \\
\text { Sede Central }\end{array}$ & $\begin{array}{l}\text { Habilidades } \\
\text { Comunicativas } \\
\text { para el } \\
\text { Profesorado } \\
\text { en Educación } \\
\text { Primaria } \\
\text { (4) }\end{array}$ & I Bloque & & & $\begin{array}{c}\text { Artes del } \\
\text { Lenguaje } \\
\text { para } \\
\text { Educación } \\
\text { Primaria } \\
\text { (3) } \\
\text { Didáctica de } \\
\text { la Lengua en } \\
\text { el Ámbito } \\
\text { Escolar I } \\
\text { (2) } \\
\text { Didáctica de } \\
\text { la Lengua en } \\
\text { el Ámbito } \\
\text { Escolar II } \\
\text { (3) } \\
\text { Expresión } \\
\text { Creadora (3) } \\
\text { Didáctica de } \\
\text { la Lengua en } \\
\text { el Ámbito } \\
\text { Escolar III } \\
\text { (3) }\end{array}$ & $\begin{array}{l}\text { III Bloque } \\
\text { IV Bloque } \\
\text { V Bloque } \\
\text { V Bloque }\end{array}$ & $\begin{array}{l}\text { Literatura } \\
\text { Infantil } \\
\text { (3) }\end{array}$ & V Bloque \\
\hline
\end{tabular}




\begin{tabular}{|c|c|c|c|c|c|c|c|c|}
\hline \multirow{3}{*}{ Universidad } & \multicolumn{8}{|c|}{ CURSOS EN EL PLAN DE ESTUDIOS DE BACHILLERATO } \\
\hline & \multicolumn{2}{|c|}{ Español (general) } & \multicolumn{2}{|c|}{ Lectoescritura } & \multicolumn{2}{|c|}{ Didáctica de la lengua } & \multicolumn{2}{|c|}{ Literatura infantil } \\
\hline & Cursos & $\begin{array}{l}\text { Ubicación } \\
\text { curricular }\end{array}$ & Cursos & $\begin{array}{l}\text { Ubicación } \\
\text { curricular }\end{array}$ & Cursos & $\begin{array}{l}\text { Ubicación } \\
\text { curricular }\end{array}$ & Cursos & $\begin{array}{l}\text { Ubicación } \\
\text { curricular }\end{array}$ \\
\hline $\begin{array}{l}\text { Universidad de } \\
\text { San José } \\
\text { (USJ) }\end{array}$ & $\begin{array}{c}\text { Taller de } \\
\text { Comunicación } \\
\text { Oral y Escrita } \\
\text { (3) } \\
\text { Taller de } \\
\text { Expresión para la } \\
\text { Comunicación } \\
\text { (4) } \\
\text { Gramática I } \\
\text { (4) }\end{array}$ & $\begin{array}{l}\text { II Bloque } \\
\text { VI Bloque } \\
\text { VII Bloque }\end{array}$ & & & $\begin{array}{c}\text { Español } \\
\text { Básico y } \\
\text { Laboratorio } \\
\text { Pedagógico } \\
\text { (5) } \\
\text { Seminario de } \\
\text { Creatividad } \\
\text { Literaria } \\
\text { (3) } \\
\text { Laboratorio } \\
\text { Pedagógico } \\
\text { Il para la } \\
\text { Enseñanza } \\
\text { del Español } \\
\text { (5) } \\
\text { Seminario de } \\
\text { Creatividad } \\
\text { Literaria } \\
\text { Costarricense } \\
\text { (4) } \\
\text { Evaluación } \\
\text { Aplicada a la } \\
\text { Enseñanza } \\
\text { del Español } \\
\text { (3) }\end{array}$ & $\begin{array}{l}\text { II Bloque } \\
\text { VII Bloque } \\
\text { VII Bloque } \\
\text { VIII Bloque }\end{array}$ & $\begin{array}{c}\text { Taller de } \\
\text { Lectura } \\
\text { Crítica } \\
(4) \\
\text { Introducción } \\
\text { a la } \\
\text { Literatura } \\
\text { Infantil } \\
\text { (4) } \\
\text { Géneros } \\
\text { Literarios } \\
\text { (4) }\end{array}$ & VII Bloque \\
\hline $\begin{array}{c}\text { Universidad } \\
\text { Americana (UAM) }\end{array}$ & $\begin{array}{c}\text { Redacción y } \\
\text { Ortografía } \\
\text { (4) }\end{array}$ & I Bloque & $\begin{array}{l}\text { Técnicas de } \\
\text { Lectoescritura } \\
\text { (4) }\end{array}$ & II Bloque & $\begin{array}{c}\text { Destrezas del } \\
\text { Idioma } \\
(4) \\
\text { Expresión } \\
\text { Creadora } \\
\text { (4) }\end{array}$ & $\begin{array}{l}\text { III Bloque } \\
\text { VI Bloque }\end{array}$ & $\begin{array}{l}\text { Literatura } \\
\text { Infantil } \\
\text { (4) }\end{array}$ & V Bloque \\
\hline
\end{tabular}

Continúa... 


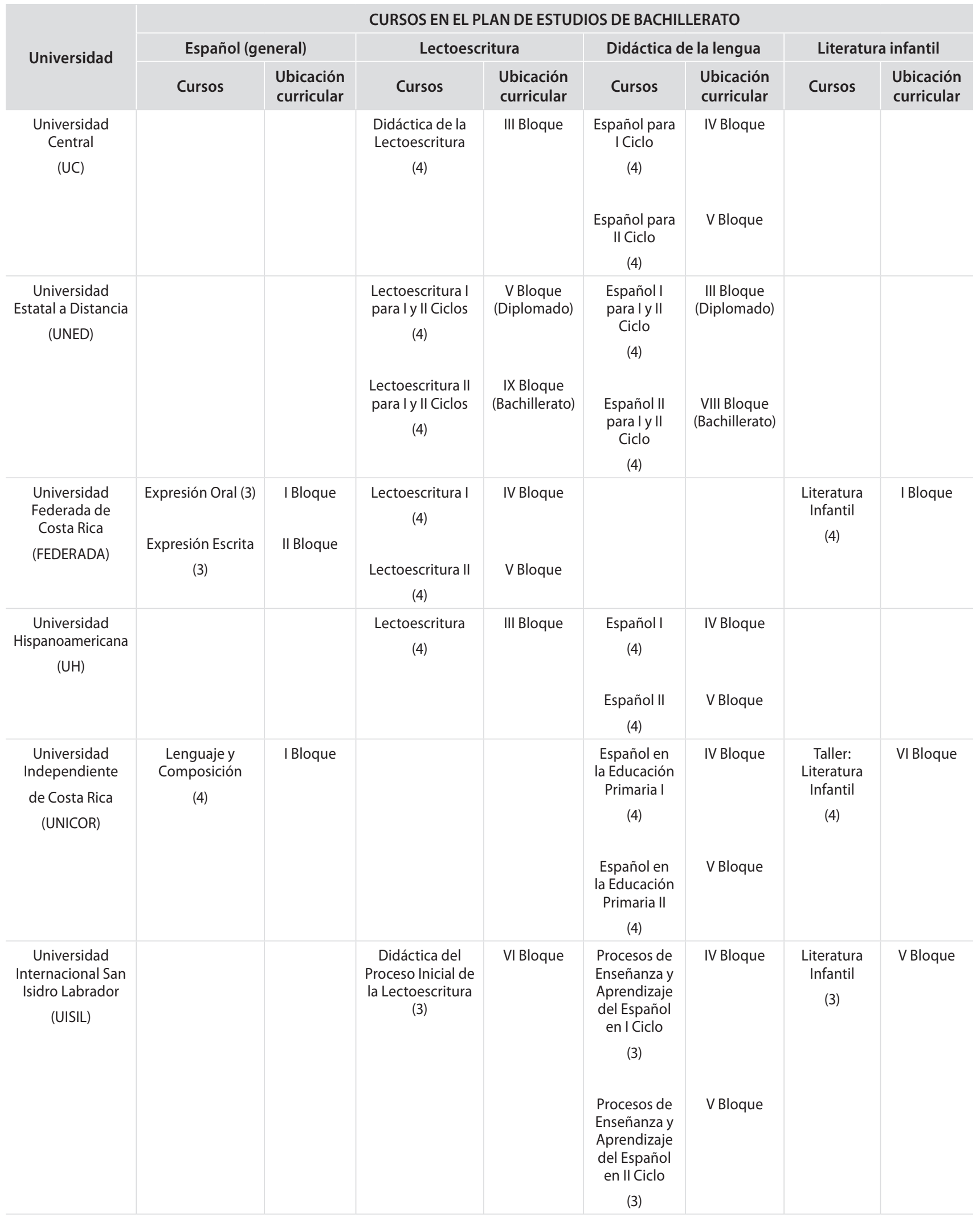




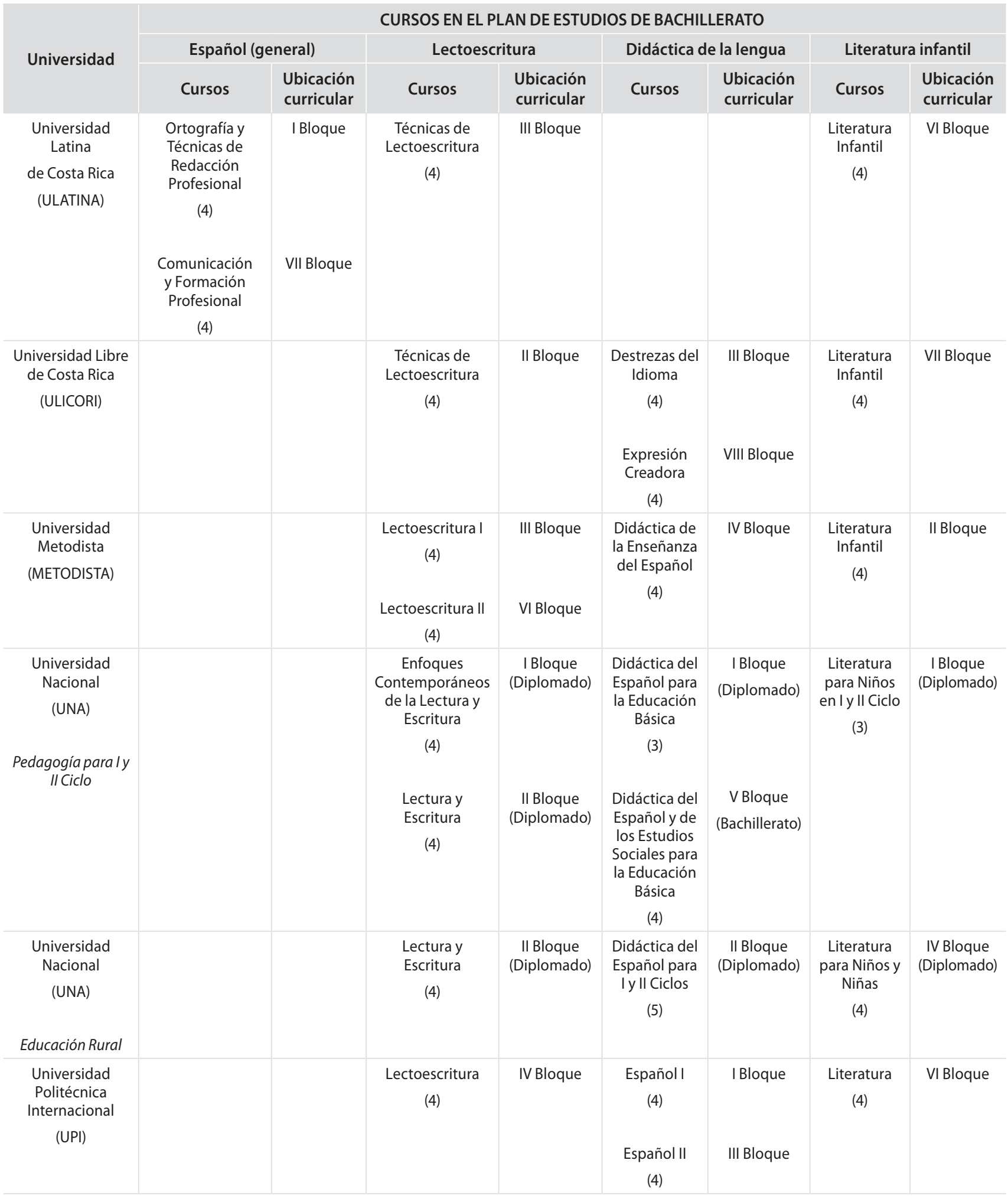

Continúa... 


\begin{tabular}{|c|c|c|c|c|c|c|c|c|}
\hline \multirow{3}{*}{ Universidad } & \multicolumn{8}{|c|}{ CURSOS EN EL PLAN DE ESTUDIOS DE BACHILLERATO } \\
\hline & \multicolumn{2}{|c|}{ Español (general) } & \multicolumn{2}{|c|}{ Lectoescritura } & \multicolumn{2}{|c|}{ Didáctica de la lengua } & \multicolumn{2}{|c|}{ Literatura infantil } \\
\hline & Cursos & $\begin{array}{l}\text { Ubicación } \\
\text { curricular }\end{array}$ & Cursos & $\begin{array}{l}\text { Ubicación } \\
\text { curricular }\end{array}$ & Cursos & $\begin{array}{l}\text { Ubicación } \\
\text { curricular }\end{array}$ & Cursos & $\begin{array}{l}\text { Ubicación } \\
\text { curricular }\end{array}$ \\
\hline $\begin{array}{l}\text { Universidad Santa } \\
\text { Lucía } \\
\text { (USL) }\end{array}$ & & & $\begin{array}{l}\text { Didáctica de la } \\
\text { Lectoescritura } \\
\text { (4) }\end{array}$ & III Bloque & $\begin{array}{l}\text { Español para } \\
\text { I Ciclo (4) } \\
\\
\text { Español para } \\
\text { || Ciclo (4) }\end{array}$ & $\begin{array}{l}\text { II Bloque } \\
\text { III Bloque }\end{array}$ & $\begin{array}{l}\text { Literatura } \\
\text { Infantil } \\
\text { (4) }\end{array}$ & VI Bloque \\
\hline
\end{tabular}

Fuente: Elaboración propia (2019) con datos de cada programa universitario en estudio.

La tabla 2 ofrece una idea inicial de las disparidades entre los 19 programas de estudio analizados en cuanto a intensidad (creditaje) de la formación en materia de lectoescritura, lengua española general, didáctica de la lengua y literatura infantil de las futuras docentes y los futuros docentes, la cual se presenta en la figura 1.

Figura 1. Número de créditos por universidad dedicados a las áreas de lectoescritura, español general, didáctica de la lengua española y/o literatura infantil durante la formación inicial (bachillerato) en Educación para I y II Ciclos

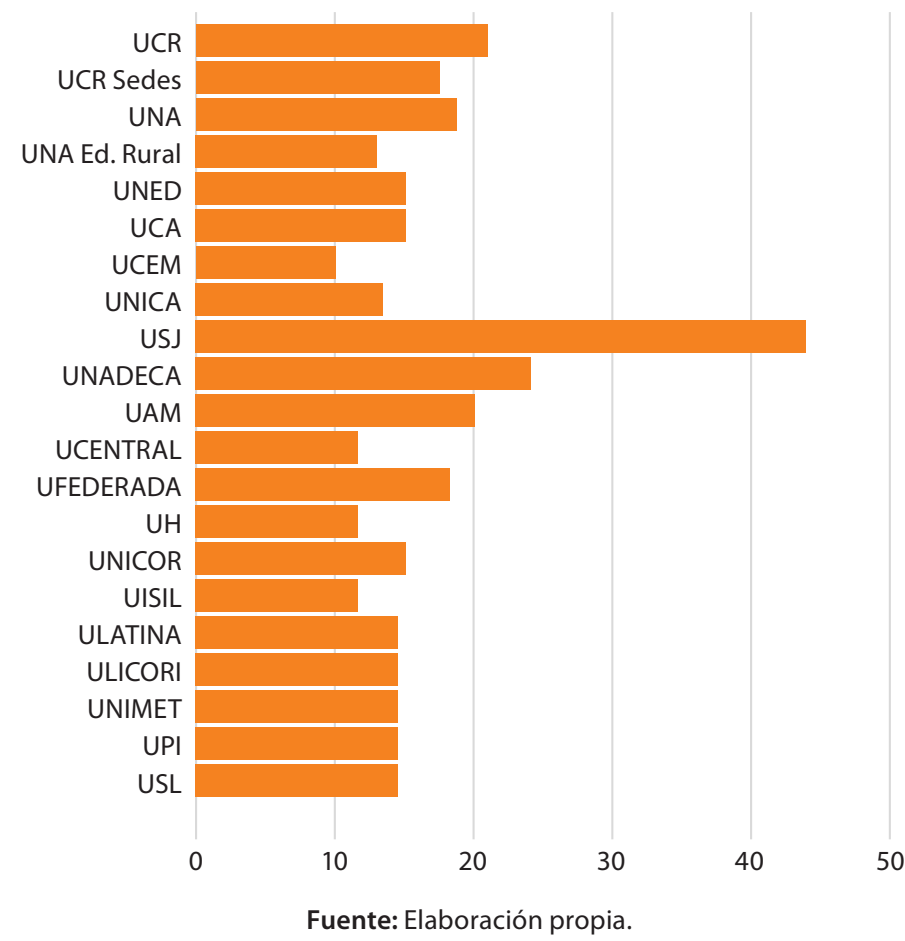

Como se muestra en la figura 1, la mayoría de los programas universitarios analizados tienen 20 créditos o menos dentro de las áreas de lectoescritura, español general, didáctica de la lengua española y/o literatura infantil en el itinerario formativo inicial (nivel de bachillerato) para docentes de Educación en I y II Ciclos; de hecho - a manera de ilustración descriptiva - la medida estadística "moda" del conjunto de datos es de 16 créditos (MS-Excel 2007) por lo que es el valor común en cuanto a suma del número de créditos dedicados a las áreas de lectoescritura, español general, didáctica de la lengua española y/o literatura infantil durante el itinerario de formación inicial (Bachillerato) en Educación para I y II Ciclos. 
El programa de estudios de la Universidad de San José (USJ) merece mención aparte pues suma más del doble que las demás (43 créditos) y es - como se puede observar en el cuadro 2 - el único que incluye dos seminarios de creatividad literaria (general y costarricense), así como un curso de géneros literarios; si bien esto podría atribuirse a que otorga una titulación denominada Bachillerato en Enseñanza Primaria con Énfasis en Español, es de notar que la situación no se presenta en otras instituciones cuyo título también consigna el énfasis por materia, como la Universidad Independiente de Costa Rica (UNICOR).

Se analizará a continuación, a partir de los datos de la figura 2, la cantidad de cursos de la línea de español (general) en los planes de estudio analizados.

Figura 2. Cantidad de cursos por universidad dedicados al área de español (general) durante el itinerario de formación inicial (bachillerato) en Educación para l y II Ciclos

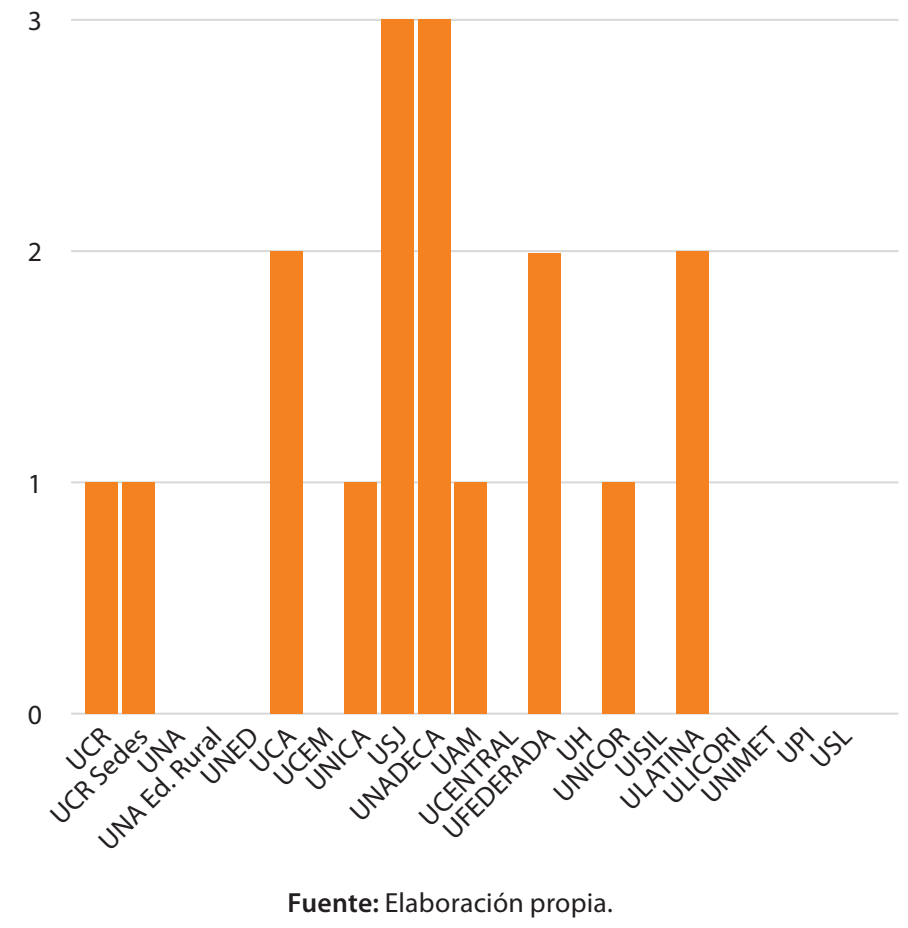

Llama la atención que las dos universidades con mayor número de créditos en su plan de estudios que se dedican a las áreas de lectoescritura, español (general), didáctica de la lengua y/o literatura infantil son - a pesar de no tener ningún curso expresamente llamado "Lectoescritura", tal como se vio en la figura 6 - las que mayor cantidad de cursos tienen en el área de español (general) y las que incluyen preparación en comunicación oral y escrita, redacción y ortografía y/o habilidades comunicativas en general, tal como se muestra en el cuadro 2. Se infiere - al inspeccionar la malla curricular - que estos dos programas de estudio (USJ y UNADECA) buscan formar a una persona docente con habilidades comunicativas sólidas, lo que - aunque no se relaciona en forma directa con el estímulo a su identidad lectora - da cuenta de una visión más integral del papel del lenguaje y de la comunicación en la profesión docente.

El hallazgo de la aparente ausencia de preparación integral en comunicación y lenguaje de la persona docente cobra vigencia si se contrasta con hallazgos previos como los de Doris Chavarría, David Fernández, Marcelo Gaete y Miriam Masís (2013), quienes afirman que la formación académica docente se valora diferente por parte de directoras/es, madres y padres de familia y estudiantes pero que, en todo caso, se considera que - sin importar la universidad de proveniencia - la persona docente debe "reaprender en las aulas, porque en general no llegan del todo bien formados" pues "el currículo de las universidades está retrasado", por lo cual (al personal nuevo) "hace falta enseñarles cómo se llega a dar clase" (op.cit.).

\section{(c) $(1) \Theta$}


En las mallas curriculares, se observa que todas las universidades que cuentan con cursos en el área de español (general) y preparan a las/os futuras/os docentes en sus propias destrezas de comunicación y lenguaje, ubican las materias citadas en el primer año del plan de estudios, mayoritariamente en el primer bloque de la carrera. Pareciera entonces que se busca remediar carencias en el área que se arrastran desde la educación secundaria y, a la vez, posicionar las destrezas comunicativas de las/os futuras/os docentes desde el inicio de su itinerario formativo.

En este sentido, aunque no se cuenta con investigaciones específicas en lectura y/o escritura en estudiantes de primer ingreso de Educación para I y II Ciclos, cabe mencionar que estudios previos con población universitaria como el de Eliana Montero, Shirley Rojas, Evelyn Zamora y Ana María Rodino (2012) concluyen que es imperativo enseñar estrategias de lectura para la comprensión de textos y fomentar el hábito de lectura en la población colegial costarricense para que, al llegar a la universidad, no manifiesten que no comprenden los textos asignados a nivel universitario, como indica el estudio de Nancy Mora et al. (2014).

Se analizará a continuación, a partir de los datos de la figura 3 la cantidad de cursos de la línea de lectoescritura en los planes de estudio analizados.

Figura 3. Cantidad de cursos por universidad dedicados al área de lectoescritura durante el itinerario de formación inicial (bachillerato) en Educación para l y ll Ciclos

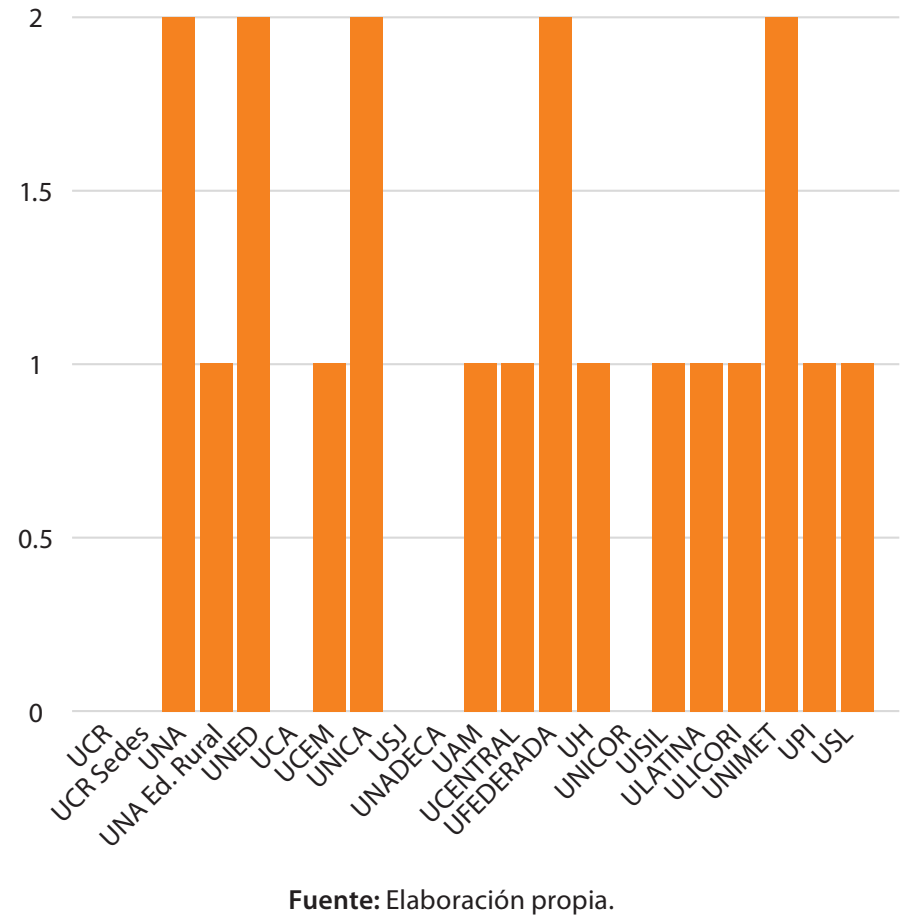

La figura 3 muestra que las universidades con mayor número de créditos - tanto a nivel general del programa de bachillerato como en materias de las áreas de lectoescritura, español general, didáctica de la lengua española y/o literatura infantil - no poseen cursos cuyo nombre y objetivo los coloque como exclusivos del área de lectoescritura; tal es el caso de la Universidad de Costa Rica (UCR), tanto en Sede Central como en Sedes Regionales; de la Universidad de San José (USJ), cuyo plan de estudios ya se comentó anteriormente por su creditaje en las áreas antes mencionadas; y de la Universidad Adventista de Centroamérica (UNADECA), lo cual podría inferir un trato más integral - menos instrumentalmente aislado - de la destreza. 
En constraste, de la revisión de los objetivos generales de las instituciones cuyo plan de estudios sí tiene cursos denominados expresamente como "Lectoescritura", parece que en estos la enseñanza de la lectoescritura se aborda desde el enfoque de enseñanza directa - cuyo planteamiento jerárquico sostiene que ciertas habilidades sirven de antecedentes para desarrollar otras y, por tanto, la enseñanza debe respetar cierta secuencia - el cual emplea el concepto de "conciencia fonológica" como base al suponer que el sistema alfabético de escritura es una transcripción de sonidos, por lo que para aprender a leer y a escribir lo esencial es identificar esos sonidos y asociar cada uno con la letra correspondiente (planteamiento que se ha considerado "no auténtico" en el sentido de que segmentar el lenguaje en sonidos (fonemas) para centrarse en la correspondencia letra/grafía no es parte de ninguna situación comunicativa real, ver nota 3).

La figura 4 presenta la cantidad de cursos de didáctica de la lengua española en los programas analizados.

Figura 4. Cantidad de cursos por universidad dedicados al área de didáctica de la lengua española durante el itinerario de formación inicial (bachillerato) en Educación para I y II Ciclos

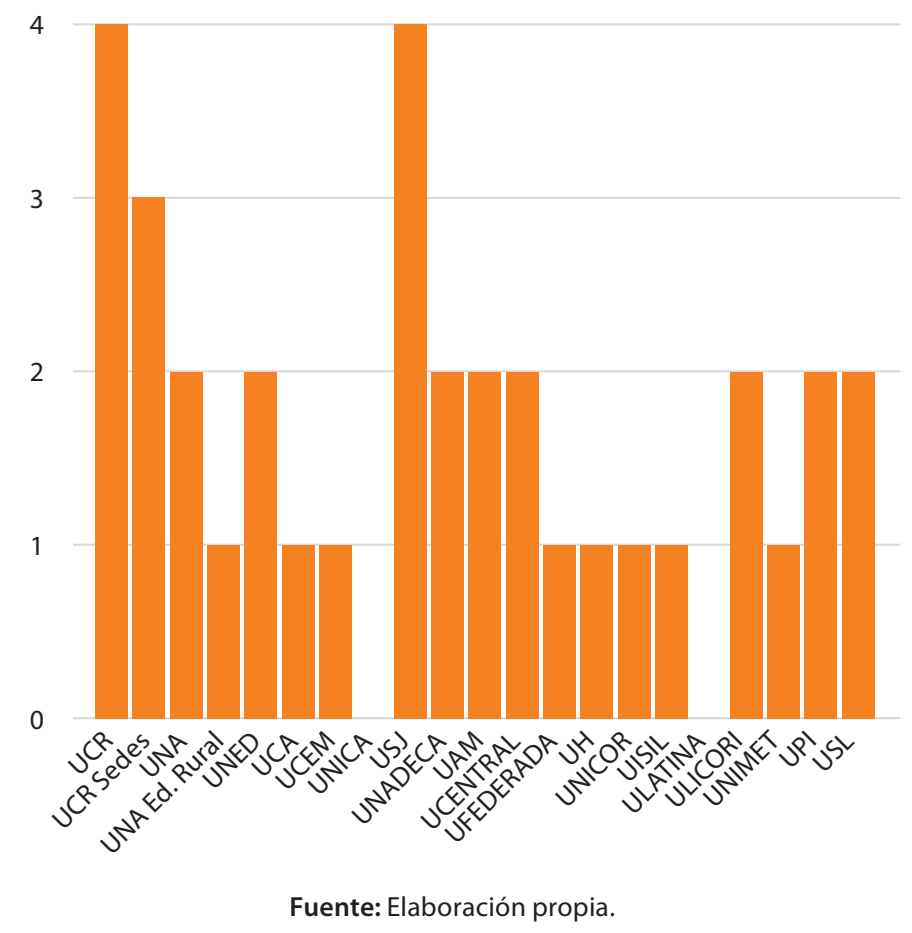

La descripción de la cantidad de cursos que integran la línea de didáctica del español / de la lengua española expresa - aún si es de forma preliminar - una tendencia a que las universidades con mayor cantidad de cursos de español (general) sean también las que mayor cantidad de cursos y de créditos tienen en el área de didáctica del español, como es el caso de la UCR (tanto en Sede Central como en Sedes Regionales) y de la USJ. Lo anterior, podría indicar una posible relación entre percibir la comunicación y la lengua de forma más integral en la formación de las y los futuras/os docentes y profundizar su preparación especializada para enseñarla.

Cabe resaltar que, para Marielos Murillo y Ana María Carmiol (2008) la investigación empírica sobre la relación entre formación docente y aprendizaje de la lectoescritura en aulas no se ha desarrollado en Costa Rica. Se cuenta con un estudio pionero de la International Reading Association (IRA) - realizado por medio de su Comisión Nacional para la Excelencia en la Preparación de Docentes para la Enseñanza de la Lectura - que comparó los logros de docentes en servicio graduados de programas de formación de alta calidad y docentes graduados de programas que no recibieron esa distinción para afirmar que 
- según su formación - las docentes y los docentes emplean estrategias más o menos congruentes con los métodos de enseñanza que la investigación señala como los más adecuados, posiblemente como consecuencia de las diferencias en el tiempo dedicado a la instrucción para la enseñanza de la lengua que existe entre las universidades.

En cuanto al posicionamiento de estos cursos de didáctica de la lengua española en las respectivas mallas curriculares, se encontró que la vasta mayoría de universidades cuenta con cursos en el área de didáctica del español / didáctica de la lengua española - de hecho, sólo tres de los 19 programas (UNICA, UFEDERADA y ULATINA) no los tienen - pero llama la atención que la mayoría se ubican antes del cuarto bloque del programa respectivo.

Únicamente, en dos instituciones - UNADECA y UCEM - se posicionan en bloques posteriores (sétimo y sexto, respectivamente). Esta situación, vista en el panorama amplio del análisis de las mallas curriculares que indica que no existen cursos previos de sensibilización o animación a la lectura y/o de lectura como habilidad transversal, puede correlacionarse con el llamado Efecto Pedro (Peter Effect) identificado por Anthony Applegate y Mary Dekonty Applegate (2004) al concluir que las y los docentes en formación se enfrentan a la tarea de promover en sus estudiantes una identidad lectora que ellas/os mismas/os no poseen y que, por tanto, les es prácticamente imposible inspirar y estimular (los autores denominan este fenómeno como el Efecto Pedro en relación a la parábola bíblica (Hechos 3:5) en la que un paralítico de nacimiento pide dinero al apóstol Pablo y este le replica que "no es posible dar lo que no se tiene").

Por último, como parte del análisis cuantitativo de los planes de estudio, se presenta en la figura 5 el número de cursos en el área de literatura infantil de los 19 programas de estudio incluidos en la investigación.

Figura 5. Cantidad de cursos por universidad dedicados al área de literatura infantil durante el itinerario de formación inicial (Bachillerato) en Educación para I y II Ciclos

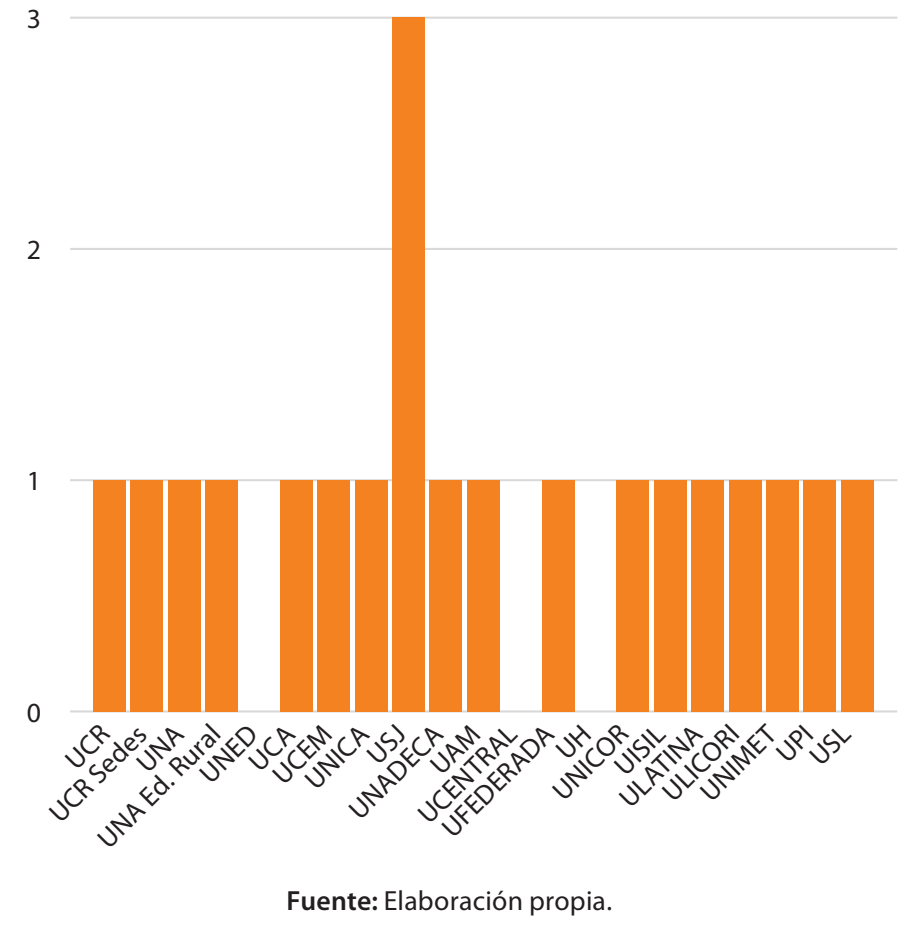

Con excepción de la Universidad de San José (USJ), que cuenta con tres cursos en esta área, las universidades ofrecen esta formación por medio de un solo curso de literatura infantil e incluso existen tres programas de estudio de los diecinueve analizados - una universidad pública, UNED, y dos universidades privadas, 
UCENTRAL y UH - que no brindan ningún curso en esta área lo que sugiere que en estas instituciones la literatura se encuentra ausente en el itinerario formativo.

Del mismo modo, el análisis del posicionamiento de estos cursos de Literatura Infantil en las respectivas mallas curriculares resalta que la mayoría - once de diecinueve - de planes de los estudio colocan el curso de Literatura Infantil a partir del cuarto bloque de la carrera y, generalmente, cuando se han llevado los cursos - o al menos uno - de Lectoescritura y/o de Didáctica de la Lengua Española. Esto sugiere que la literatura infantil se visualiza como culminación de la línea de formación en Español, lo cual expresa una visión lineal y/o jerarquizada donde "leer literatura" se enseña posterior a otros aprendizajes lingüísticos considerados elementales - puntuación, ortografía y gramática, por ejemplo - y no como habilidad transversal de construir y deconstruir la visión de mundo y actividad de carácter extensivo.

\section{CONCLUSIONES}

El mapeo realizado de programas universitarios arroja que en Costa Rica existen 26 programas universitarios autorizados como titulaciones de nivel inicial en Educación para I y II Ciclos (3 universidades públicas y 23 universidades privadas), pero en la actualidad sólo se ofrecen 19 programas (3 universidades estatales y 16 universidades privadas) pues ocho universidades privadas han optado por solo mantener abierta la matrícula en los programas con concentración en inglés, hecho que plantea potencialmente otro reto país en materia de lectoescritura en L1 (español) pues implica que un porcentaje importante de docentes de primaria que hoy se forman en universidades privadas reciben la formación en didáctica de la lengua para una L2 (inglés) y no para su L1 (español).

Debe resaltarse que solamente los programas de estudio ofrecidos por universidades estatales - 3 instituciones de 19 que ofrecen formación docente inicial en Educación para I y II Ciclos - han sido acreditados por parte del Sistema Nacional de Acreditación de la Educación Superior (SINAES) y, por tanto, se han sometido a evaluación externa de sus planes de estudio y de sus comunidades académicas. Asimismo, si bien la carga más alta de créditos pertenece a un programa de estudios de una universidad estatal (UCR), la diferencia de créditos no obedece necesariamente a un mayor número de cursos especializados, sino a la llamada formación transversal (cursos integrados de humanidades, repertorios, etc.).

Luego, llama la atención de este primer análisis cuantitativo de las mallas curriculares que la mayoría ( $\mathrm{n}=11$ ) de planes de estudio de titulación inicial docente para I y II ciclos centran su atención en las didácticas - ya sea de lectoescritura, de lengua o ambas - sin preparar previamente a la persona docente en formación en destrezas lingüísticas generales y/o promover sus propios hábitos de lectura extensiva por medio de acciones formativas específicas en cultura lectora a nivel de plan de estudios - categoría llamada "Español (general)" - lo cual podría indicar que estas instituciones favorecen la enseñanza de la lectoescritura y la lectura desde un abordaje más instrumental que desde el desarrollo previo de destrezas lingüísticas en la persona docente en formación, incluyendo la lectura como habilidad transversal.

\section{Notas del texto:}

Nota 1: Tal como lo detalla Leonel Obando (2008) en "Selección de personal para la educación pública: el caso de Costa Rica", si bien la Ley de Carrera Docente (1970) establece los grupos profesionales PT-1, PT-2, PT-3, PT-4, PT-5 y PT-6 (donde el PT-1 corresponde al grupo de menor categoría y PT-6 al de mayor) para la enseñanza primaria y en estos solamente hay titulación universitaria de PT-3 en adelante pues PT-3 equivale a profesorado, PT-4 a diplomado, PT-5 a bachillerato y PT-6 a licenciatura, la descripción actual (1999 en adelante) de puestos de la Dirección General del Servicio Civil en Costa Rica es clara en que el grado mínimo actual para ser nombrado docente en el Ministerio de Educación Pública es de Bachiller. Para mayor referencia, puede visitarse la sección de "Clases y 
especialidades docentes" de la Dirección General de Servicio Civil en: http://www.dgsc.go.cr/ts_clase_docente/ dgsc_servicios_docente.html

Asimismo, llama la atención que, a pesar de este cambio, la mayoría de universidades hoy ya no ofrecen salidas laterales - o no las promocionan como alternativas de formación en sus itinerarios de estudio - pues consignan el grado de bachiller como la titulación inicial, el Colegio de Licenciados y Profesores en Letras, Filosofía, Ciencias y Artes de Costa Rica (COLYPRO) sí acepta la afiliación de personas docentes con el grado de profesorado en adelante, tal como se detalla en la sección de "Requisitos de incorporación" del ente: http://www.colypro.com/incorporaciones/ requisitos-de-incorporacion.app

Nota 2: Debe notarse que, durante la revisión de los programas de los cursos, se encontró que algunos de estos incluían un contenido bajo un nombre más general (por ejemplo, los contenidos de Literatura Infantil en la asignatura Español II de la Universidad Estatal a Distancia y el mismo caso en la Universidad Central y en la Universidad Hispanoamericana). No obstante, para efectos de la categorización y siguiendo el razonamiento deductivo, se decidió continuar con el nombre del curso y su objetivo general - aspectos invariables en los programas - como principales criterios de clasificación pues la autora considera que el hecho de que la literatura infantil se enseñe como un contenido más dentro de una asignatura y no como una asignatura en sí misma revela el acercamiento que el programa mismo da a ese contenido dentro de la formación de las futuras docentes y los futuros docentes.

Nota 3: Para mayor referencia, ver el texto de Sofía Vernon (s.f.) Tres distintos enfoques en las propuestas de alfabetización inicial. La autora presenta el enfoque de enseñanza directa - antes descrito - como radicalmente opuesto al enfoque del lenguaje integral, que afirman que el aprendizaje de la lengua escrita es un aprendizaje "natural" por lo que, así como cualquier persona aprende a hablar sin que se le enseñe explícitamente a hacerlo porque está rodeado de personas que usan su lengua para comunicarse - asimismo la persona que vive en un medio social donde se usa la escritura como medio de comunicación aprenderá a leer y escribir porque necesita comunicarse, por lo que el infante debe estar inmerso en un medio en el cual la lengua escrita se use con propósitos reales, se lean textos reales (no letras, sílabas, palabras y oraciones aisladas), se utilice la información no visual (conocimiento del lenguaje, del tema, del tipo de texto ) como elemento de comprensión y se permita a la persona aprendiz - con la guía de la persona docente - regular su propio aprendizaje y de cooperar con otras personas en el mismo proceso para que el aprendizaje sea social. Luego, resulta claro que el enfoque de enseñanza directa y el enfoque del lenguaje integral son totalmente opuestos (comprensión vs. decodificación, transacción en la enseñanza vs. enseñanza directa, entre otros).

\section{REFERENCIAS}

Applegate, A.J. y Applegate, M.D. (2004). The Peter Effect: Reading habits and attitudes of preservice teachers. En: The Reading Teacher, 57(6), 554-563. Online publication. Retrieved from: https:// thoughtfulliteracy.com/Applegate\%20and\%20Applegate,\%202004\%20The\%20Peter\%20Effect.pdf

Benevides, T. y Peterson, S. (2010). Literacy attitudes, habits and achievements of future teachers. Journal of Education for Teaching, 36(3), 291-302. Online publication. Retrieved from: https://www. tandfonline.com/doi/abs/10.1080/02607476.2010.497375

Boggs, M. y Golden, F. (2009). Insights: Literacy memories of preservice teachers self-reported categories of impact. The Reading Matrix, 9(2), 211-223. Online publication. Retrieved from: http://www. readingmatrix.com/articles/sept_2009/boggs_golden.pdf

Cerdas, D. (2016). Costa Rica desmejora en Matemáticas, Ciencias y Lectura en pruebas internacionales. Nota periodística del 06 de diciembre de 2016. Recuperada de: https://www.nacion.com/el-pais/ educacion/costa-rica-desmejora-en-matematicas-ciencias-y-lectura-en-pruebas-internacionales/ LXE5GXQMMFHU3KKVQJTKL2ARAY/story/

Cerdas, D. (2020). Futuros docentes deberán tener estas 11 características para ser contratados por el MEP. Nota periodística del 21 de febrero de 2020. Recuperada de: https://www.nacion.com/el-pais/ educacion/futuros-docentes-deberan-tener-estas-11/IEJ4NXM2YJEXJPXQSUHWJO7GO4/story/ 
Cerdas, D. (2017a). OCDE señala "poca mejora" en estudiantes ticos pese a alta inversión. Nota periodística del 03 de agosto de 2017. Recuperada de: https://www.nacion.com/el-pais/educacion/ ocde-senala-poca-mejora-en-estudiantes-ticos-pese-a-alta-inversion/3TSAQYOMRND7LDLET7 WRQRYCCA/story/

Cerdas, D. (2017b). "Recortar en educación sería dispararnos en el pie". Entrevista con Isabel Román, coordinadora del Estado de la Educación en Costa Rica. Nota periodística del 02 de septiembre de 2017. Recuperada de: https://www.nacion.com/el-pais/educacion/estado-de-la-educacionrecortar-en-materia-educativa-seria-dispararnos-en-el-pie/N4VBW7GLJ5AZ5DATXDECEXATCE/ story/

Cerdas, D. (2019). Al 74\% de maestros ni les gusta leer ni fomentan el hábito en los niños. Nota periodística del 21 de agosto de 2019. Recuperada de: https://www.nacion.com/el-pais/educacion/ al-74-de-maestros-ni-les-gusta-leer-ni-fomentan/LNSMMXPTCJHXDCIWDMHCWH7XP4/story/

Chacón, V. (2016). Costa Rica deficiente en pruebas PISA. En: Semanario Universidad. Nota periodística del 06 de diciembre de 2016. Recuperada de: https://semanariouniversidad.com/pais/ costa-rica-deficiente-pruebas-pisa/

Chavarría, D., Fernández, D., Gaete, M., Masís, M. (2013). Dignificación de la profesión docente y valoración social del profesorado en Costa Rica. Departamento de Estudios e Investigación Educativa del Ministerio de Educación Pública (MEP). Publicación en línea. Recuperada de: https://www.mep. go.cr/sites/default/files/dignificacion_profesion_docente.pdf

Colegio de Licenciados y Profesores en Letras, Filosofía, Ciencias y Artes de Costa Rica. (COLYPRO). Requisitos de incorporación. Publicación en línea. Recuperada de: http://www.colypro.com/ incorporaciones/requisitos-de-incorporacion

Consejo Nacional de Enseñanza Superior Universitaria. (CONESUP). (2018). Listado y oferta académica de universidades privadas autorizadas en Costa Rica a agosto 2018. Publicación en línea. Recuperada de: http://www.conesup.mep.go.cr/lista_universidades

Consejo Nacional de Enseñanza Superior Universitaria. (CONESUP). (2018). Programas autorizados para Bachillerato en I y II Ciclo en las Universidades: UCA, UCEM, ÚNICA, USJ, UNADECA, UAM, UC, UFEDERADA, UH, UNICOR, UISIL, ULATINA, ULICORI, UMETODISTA, UPI y USL.

Consejo Nacional de Rectores. (CONARE). (2018). Estadísticas de Educación Superior. Publicación en línea. Recuperada de: https://www.conare.ac.cr/servicios/estadistica

Consejo Nacional de Rectores. (CONARE). (2018). Programas autorizados para Bachillerato en I y II Ciclo en las Universidades: UCR, UNA y UNED.

Conway, P.F., Rutherford, V. (2013). Learning Place Practices and Pre-service Teacher Education in Ireland: Knowledge Generation, Partnerships and Pedagogy. En: O. McNamara et al. (eds.), Workplace Learning in Teacher Education. Springer Science+Business Media Dordrecht 2014. Online publication. Retrieved from: https://www.researchgate.net/publication/299135733_Learningplace'Practices _and_Pre-service_Teacher_Education_in_Ireland_Knowledge_Generation_Partnerships_and_ Pedagogy

Daisey, P. (2009). The reading experiences and beliefs of secondary preservice teachers. En: Reading Horizons, 49(2), 167-190. Online publication. Retrieved from: https://scholarworks.wmich.edu/ cgi/viewcontent.cgi?referer=https://www.google.com/\&httpsredir=1\&article=1053\&context=re ading_horizons

Dirección General de Servicio Civil de Costa Rica (DGSC). (2019). Clases y especialidades docentes. Publicación en línea. Recuperada de: http://www.dgsc.go.cr/ts_clase_docente/dgsc_servicios_ docente.html

Gamboa, A., Muñoz, P., Vargas, L. (2016). Literacidad: nuevas posibilidades socioculturales y pedagógicas para la escuela. En: Revista Latinoamericana de Estudios Educativos. 12(1), pp 53-70- Publicación en línea. Recuperada de: http://www.redalyc.org/pdf/1341/134149742004.pdf 
Granado, C., Puig, M. (2015). La identidad lectora de los maestros en formación como componente de su identidad docente: un estudio de sus autobiografías como lectores. En: OCNOS Revista de Estudios sobre Lectura. No. 13. Publicación en línea. Recuperada de: https://www.revista.uclm.es/ index.php/ocnos/article/view/ocnos_2015.13.03/pdf

Grupo Lenguaje, Educación y Desarrollo (LED) de la Universidad de Antioquía. (2008). Impacto de la formación de maestros en competencias en el área del lenguaje. En: Lingüística y Literatura, No. 53. Publicación en línea. Recuperada de: https://aprendeenlinea.udea.edu.co/revistas/index.php/ lyl/article/viewFile/971/4537

Montero, E., Rojas, S., Zamora, E., Rodino, A.M. (2012). Costa Rica en las pruebas PISA 2009 de Competencia Lectora y Alfabetización Matemática. Cuarto Informe Estado de La Educación. Publicación en línea. Recuperada de: https://estadonacion.or.cr/files/biblioteca_virtual/educacion/004/montero\%20 et\%20al_pisa\%20competencia\%20lectora\%20y\%20alfabetizacion\%20matematica.pdf

Mora, N., Moraga, L., Murcia, R., Porras, K., Quesada, W., Solano, K. (2014). El fomento de la lectura a nivel universitario: propuesta de un programa de alfabetización lectora para la Escuela de Estudios Generales de la Universidad de Costa Rica. Universidad de Costa Rica. Publicación en línea. Recuperada de: http://www.kerwa.ucr.ac.cr/bitstream/handle/10669/29117/Fomento\%20 de\%20la\%20lectura\%20a\%20nivel\%20universitario.pdf?sequence=2\&isAllowed=y

Murillo, M., Carmiol, A.M. (2008). La enseñanza de la Lengua Española y la formación docente en la educación primaria costarricense. En: Segundo Informe Estado de la Educación. San José, Programa Estado de la Nación. Publicación en línea. Recuperada de: https://www.estadonacion.or.cr/ informe-ii-estado-educacion

Murillo, M. et al. (2018). Concepciones de los docentes acerca de la enseñanza de la lectura y la escritura y la implementación del Programa de Español en las aulas. Ponencia preparada para el Séptimo Informe Estado de la Educación. San José: PEN.

Obando, L. (2008). Selección de personal para la educación pública: el caso de Costa Rica. Documento presentado en el XIV Foro de la Función Pública del Istmo Centroamericano, Panamá y República Dominicana: “Profesionalización de la Función Pública y Gestión de Calidad”, realizado del 16 al 18 de julio del 2008 en Santo Domingo (República Dominicana) y organizado por el Instituto Centroamericano de Administración Pública (ICAP) y la Secretaría de Estado de Administración Pública (SEAP) de República Dominicana. Publicación en línea. Recuperada de: http://unpan1. un.org/intradoc/groups/public/documents/icap/unpan035280.pdf

Organización de Estados Iberoamericanos para la Educación, la Ciencia y la Cultura. (OEI). (s.f.). Organización y estructura de la formación docente en Costa Rica. Documento de trabajo. Publicación en línea. Recuperada de: https://www.oei.es/historico/quipu/costarica/informe_docentes.pdf

Organización de las Naciones Unidas para la Ciencia, la Educación y la Cultura. (UNESCO). (2015). Informe de Resultados TERCE - Tercer Estudio Regional, Comparativo y Explicativo. Publicación en línea. Recuperada de: http://unesdoc.unesco.org/images/0024/002435/243532S.pdf

Presidencia de la República de Costa Rica. (2015). Costa Rica: inversión en educación más alta de América Latina: $\$ 1.7$ millones por estudiante al año. Comunicado de prensa del 28 de abril de 2015. Recuperado de: https://presidencia.go.cr/comunicados/2015/04/costa-rica-inversion-eneducacion-mas-alta-de-america-latina-\%E2\%82\%A11-7-millones-por-estudiante-al-ano/

Programa Estado de la Nación. (PEN). (2017). Sexto Informe Estado de la Educación en Costa Rica. Publicación en línea. Recuperada de: http://www.estadonacion.or.cr/educacion2017/

Programa Estado de la Nación. (PEN). (2019). Séptimo Informe Estado de la Educación en Costa Rica. Publicación en línea. Recuperada de: https://estadonacion.or.cr/tag/septimo-informeestado-de-la-educacion/

Vernon, S. (s.f.). Tres distintos enfoques en las propuestas de alfabetización inicial. Secretaría de Educación Pública del Gobierno Federal de México. Publicación en línea. Recuperada de: https://www.dgespe. sep.gob.mx/public/pemde/lectura/tdea.pdf 